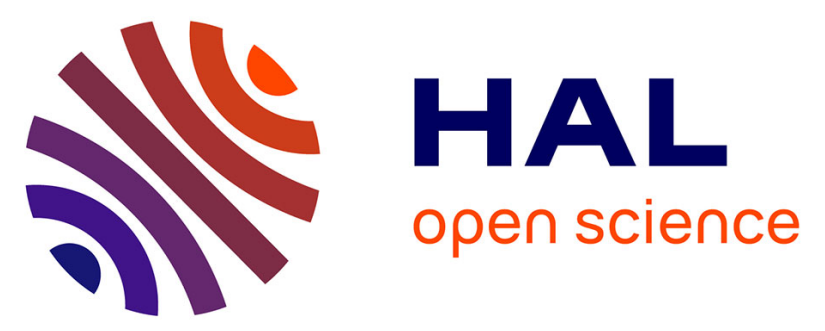

\title{
Microprocessor prosthetic ankles: comparative biomechanical evaluation of people with transtibial traumatic amputation during standing on level ground and slope.
}

Marie Thomas-Pohl, Coralie Villa, Jean-Louis Davot, Xavier Bonnet, Julia Facione, Eric Lapeyre, Joseph Bascou, Hélène Pillet

\section{To cite this version:}

Marie Thomas-Pohl, Coralie Villa, Jean-Louis Davot, Xavier Bonnet, Julia Facione, et al.. Microprocessor prosthetic ankles: comparative biomechanical evaluation of people with transtibial traumatic amputation during standing on level ground and slope.. Disability and Rehabilitation: Assistive Technology, 2019, pp.1-10. 10.1080/17483107.2019.1629112 . hal-02564072

\section{HAL Id: hal-02564072 \\ https://hal.science/hal-02564072}

Submitted on 5 May 2020

HAL is a multi-disciplinary open access archive for the deposit and dissemination of scientific research documents, whether they are published or not. The documents may come from teaching and research institutions in France or abroad, or from public or private research centers.
L'archive ouverte pluridisciplinaire HAL, est destinée au dépôt et à la diffusion de documents scientifiques de niveau recherche, publiés ou non, émanant des établissements d'enseignement et de recherche français ou étrangers, des laboratoires publics ou privés. 


\title{
Microprocessor prosthetic ankles: comparative biomechanical evaluation of people with transtibial traumatic amputation during standing on level ground and slope
}

\author{
Marie Thomas-Pohl ${ }^{a}$, C. Villa ${ }^{b, c}$, J. Davot ${ }^{b}$, X. Bonnet $^{c}$, J. Facione ${ }^{a}$, E. Lapeyre ${ }^{a}$, J. Bascou ${ }^{b, c}$ and H. Pillet ${ }^{c}$

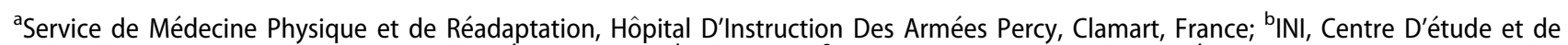 \\ Recherche Sur L'appareillage Des Handicapés (CERAH), Créteil, France; 'Arts et Metiers Institut de Biomécanique Humaine Georges Charpak, \\ Paris, France
}

\begin{abstract}
Background: The compensations occurrence due to the alteration of the posture and the gait of persons with lower limb amputation is still an issue in prosthetic fitting. Recently, prosthetic feet designed to reproduce the physiological behaviour of the ankle using a microprocessor control have been commercialized to address this issue.

Objectives: Investigate the relevance of these microprocessor prosthetic ankles (MPAs) in the ability of standing on both level and inclined surfaces.

Methods: Six persons with transtibial amputation usually fitted with energy storing and returning (ESR) foot tested three MPAs: Elan ${ }^{\circledR}$ Endolite (MPA1), Meridium ${ }^{\circledR}$ Ottobock (MPA2), ProprioFoot ${ }^{\circledR}$ Ossur (MPA3). Each MPA data acquisition was preceded of a 2 weeks adaptation period at home and followed by a 3weeks wash-out period with their ESR. Lower limb angular position and moment, Centre of Pressure (CoP) position, Ground Reaction Forces (GRF) and functional scores were collected in static, on level ground and $12 \%$ inclined slope.

Results: MPAs allowed a better posture and a reduction of residual knee moment on positive and/or negative slope compared to ESR. Results also reflect that the MPA2 allows the best control of the CoP in all situations.

Conclusions: An increased ankle mobility is associated with a better posture and balance on slope. Gait analysis would complete these outcomes.

Clinical relevance: This study compares three MPAs to ESR analysing static posture. Static analysis on level ground and slope represents the challenging conditions people with amputation have to cope with in their daily life, especially outdoors. Having a better understanding of the three MPAs behaviour could help to adequately fit the prosthesis to each patient.
\end{abstract}

> IMPLICATIONS FOR REHABILITATION

- This is a study comparing three MPAs.

- The static analysis in standard and constraining conditions (slope) reflects the balance of people with amputation in their daily life, especially outdoors.

- Having a better understanding of the behaviour of each foot could help to adequately fit the prosthesis to each patient.

\section{Background}

Even if properly fitted, persons with lower limb amputation frequently report difficulties while walking or standing [1]. The design of microprocessor prosthetic ankles (MPAs) aims to mimic physiological ankle mobility, to enhance their adaptability to various situations. Objective evaluation of these feet is essential to quantify their benefits in these situations.

At the time of the study, three MPAs were available in France: 1/The Elan ${ }^{\circledR}$ foot - Endolite combines a carbon blade and a microprocessor-controlled hydraulic ankle. In stance, it is able to reach $3^{\circ}$ of dorsiflexion (anterior mechanical stop) and $6^{\circ}$ of plantarflexion (endolite.fr). 2/The hydraulic-controlled microprocessor Meridium $^{\circledR}$ foot - Ottobock (ottobock.fr) allows up to $14^{\circ}$

\section{KEYWORDS}

Microprocessor-controlled feet; transtibial amputee; posture; ramp; centre of pressure dorsiflexion (adaptable dorsiflexion stop) and $22^{\circ}$ plantarflexion. $3 /$ The Propriofoot ${ }^{\circledR}$ - Ossur has a range of motion of $29^{\circ}$ including $18^{\circ}$ of dorsiflexion (ossur.fr). This mobility is made possible by a motorized mechanism adjusted during the swing phase (locked ankle joint in stance).

To date, benefits of some MPAs were reported during gait, in terms of joint mobility [2], reduction of compensations [3], contralateral stresses on slope [4], and reduction of energy costs [5]. However, the main subjective improvement, reported by therapists and patients, is the recovery of balance, particularly in standing position.

Maintaining balance, while walking or standing, is a multifactorial task [6] affected by transtibial amputation [7,8]. The lack of 
postural control could lead to asymmetric posture [9] and osteoarticular complications on residual and contralateral joints $[1,10-12]$. The loss of the proprioceptive receptors of the ankle leads to the decrease of control of body centre of mass displacement in the frontal plane. Moreover, due to the loss of the motor control of the ankle flexors and extensors, the sagittal torque responsible for the balance control of non-amputee people cannot be generated anymore [13] and only is directly related to the prosthetic foot design. Therefore, MPAs adaptive mobility should result in an improvement of balance particularly on slopes.

Interestingly, standing position represents $41 \%$ of daily life activities [14]. Thus, standing evaluation on both level ground and slopes is essential. Yet, only one recent study has investigated lower limb joint angle, moment and vertical ground reaction forces of four transtibial (TT) and four transfemoral amputee people wearing six prosthetic feet $\left(\right.$ Elan $^{\circledR}$, Meridium ${ }^{\circledR}$, Propriofoot ${ }^{\circledR}$, Raize $^{\circledR}$, Triton Smart Ankle ${ }^{\circledR}$ and an energy saving and return foot - ESR) while standing on level and $10^{\circ}$-inclined surfaces [15]. The authors emphasized that prosthetic ankles with a large ankle range of motion (ROM) and a dorsiflexion stop allowed a better adaptation than ESR while standing, especially on slope. However, they did not report any information on Centre of Pressure (CoP) evolution during standing. Still, the CoP excursion was shown to be essential for characterizing static stability while standing [7] and no previous work on MPAs investigated it.

The main objective of the present research was to evaluate the ability of three MPAs to adapt to the inclination of the ground by modifying the ankle angle in standing position without compromising stability. Quantitative parameters used were: joint and segment positions from foot to trunk, normal ground reaction force asymmetry residual limb joint moments and CoP motion.

\section{Methods}

\section{Participants}

The study was approved by the local ethics committee (2014A01938-39 CPP lle de France VI Groupe Hospitalier PitiéSalpêtrière). After informed consent, six persons with transtibial amputation ( 5 males and 1 female) for traumatic reasons were included in the study. The mean age was 36years old (29-64years old). All subjects have been amputated since more than 6 months and wore as their usual foot (UF) an ESR foot without microprocessor. Subject demographics and individual functional tests are shown in Table 1. It must be noticed than for one subject, only two MPAs could be evaluated because the person was unable to wear the others in his professional shoes.

\section{Procedure}

Three MPAs were tested: Elan ${ }^{\circledR}$, Propriofoot $^{\circledR}$, Meridium $^{\circledR}$, respectively referred to as MPA1, MPA2 and MPA3 hereafter. The tests were separated by a wash out period of 3 weeks with the UF. In addition, after socket and alignment validation by the expert prosthetist, the MPA test period started with an acclimatization period of 15 days before the analysis described below.

\section{Instrumental analysis}

Subjects were equipped with a set of 54 reflective markers, used to define anatomical frames attached to 13 body segments assumed to be rigid [16]. Segment and joint positions were quantified by the absolute and relative positions of these frames. As concerned intersegmental moments calculated at the ankle and knee levels, the joint centre were respectively obtained as follows: (i) the ankle joint was defined by the middle of two markers placed on the malleoli for the contralateral limb and on the mechanical foot rotation axis or the symmetric of the contralateral ankle markers for the prosthetic limb; (ii) the knee joint was defined by the middle of the two markers placed on the condyles on both limbs and (iii) hip joint centre was estimated from anthropometric regressions from the literature [17]. Markers were systematically placed by the same experimenter with particular attention to the repeatability between sessions. Particularly, photographs of marker positions were taken for each patient. 3D marker positions were captured using an optoelectronic system (Vicon 8i, $100 \mathrm{~Hz}$, Oxford Metrics, Oxford, UK). Ground reaction forces were measured by two force platforms (AMTI, $100 \mathrm{~Hz}$, Watertown, MA, USA).

First, the subject was asked to stand during $2 \mathrm{~s}$ in an anatomical position, called hereafter the reference position (Figure 1(a)). Then, the subject had to choose a natural position keeping his feet in a $40 \mathrm{~cm}$ radius circle and was asked to stand still during $20 \mathrm{~s}$. The acquisition of marker positions and force plate data was repeated three times for each of the following situations: level (Figure $1(\mathrm{~b})$ ), $12 \%\left(7^{\circ}\right)$ positive slope, (Figure $1(\mathrm{c})$ ) and $12 \%$ negative slope (Figure $1(\mathrm{~d})$ ). These acquisitions are hereafter referred as a 20 s-trials.

\section{Functional capacities analysis}

All subjects filled out simplified Activities-Specific Balance Confidence scale $(A B C)$ questionnaire [18]; associated with a semidirected interview and visual analogous scale (VAS) confidence in balance. In addition, all subjects underwent balance and mobility tests in the following order: the Berg Balance (BBS) scale [19] and the 2-min walk test (2MWT) [20].

\section{Data analysis}

Individual position relative to the position of reference was quantified for $20 \mathrm{~s}$-trials on level ground, positive and negative slopes through:

1. Sagittal angular positions of contralateral and prosthetic ankle, knee and hip joints, and pelvis and trunk segments.

Table 1. Subject data.

\begin{tabular}{|c|c|c|c|c|c|c|}
\hline & PP01 & PP02 & PP03 & PP04 & PP05 & PP06 \\
\hline \multicolumn{7}{|l|}{ Subject demographics } \\
\hline Age (years) & 29 & 30 & 64 & 29 & 29 & 35 \\
\hline Sex & $\mathrm{M}$ & M & $\mathrm{F}$ & $M$ & $\mathrm{M}$ & M \\
\hline Amputated side & $\mathrm{R}$ & $\mathrm{L}$ & $\mathrm{L}$ & $\mathrm{R}$ & $\mathrm{L}$ & $\mathrm{L}$ \\
\hline Size $(\mathrm{cm})$ & 176 & 164 & 170 & 168 & 180 & 183 \\
\hline Time for amputation (months) & 57 & 35 & 25 & 19 & 76 & 61 \\
\hline Usual Prosthetic Foot (UF) & Freedom ${ }^{\circledR}$ & Echelon ${ }^{\circledR}$ & Panthera $\AA$ & Panthera $\AA$ & Variflex® & Variflex® \\
\hline Prosthetic foot choosen* & UF or MPA3 (under choice) & MPA1 & MPA2 & UF & UF & UF \\
\hline
\end{tabular}

${ }^{*}$ Choosen after static and dynamic $s$ analysis (best compromise). Gait speed was calculated with the 2MWT.

L: left; R: right; M: male; F: female; MPA: microprocessor controlled ankle; UF: usual foot. 
(a)

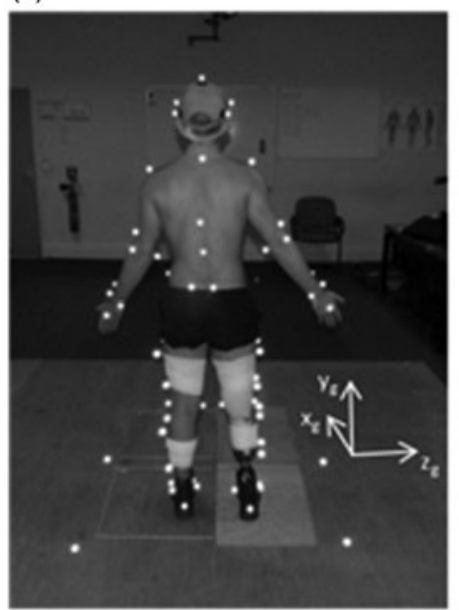

(b)

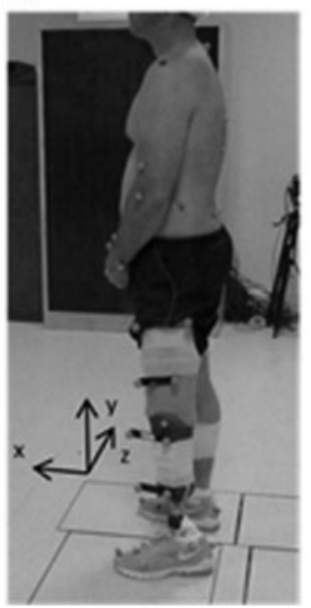

(c)

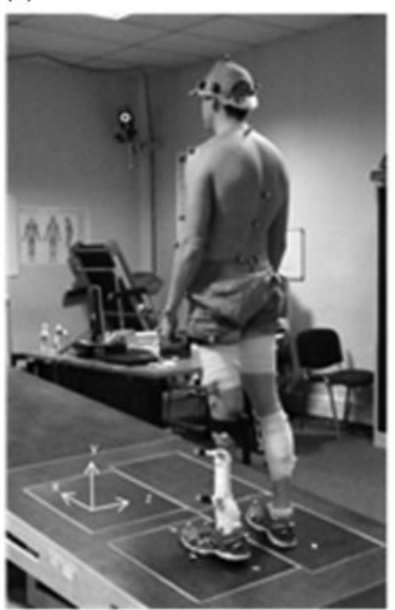

(d)

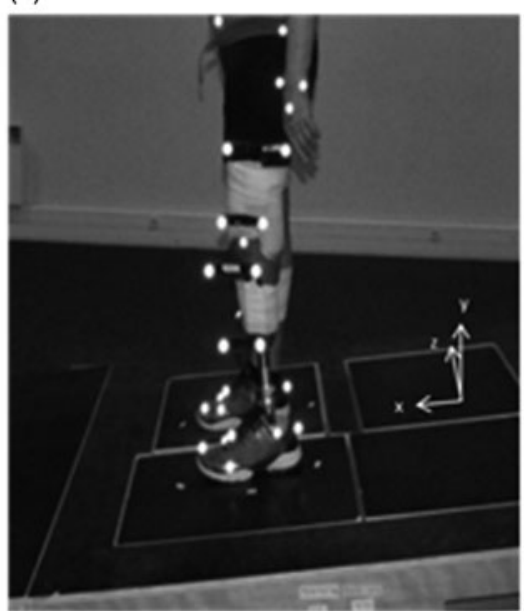

Figure 1. Anatomical position of reference (a) and $20 \mathrm{~s}$ - trials on level ground (b), on positive (c) and negative (d) slope. Global frame is represented on (a) and local frames on $(b, c, d)$. Instructions were both feet parallel to the sagittal plane, no flexion or extension of the lower limb joints and the eyes opened looking straight ahead.
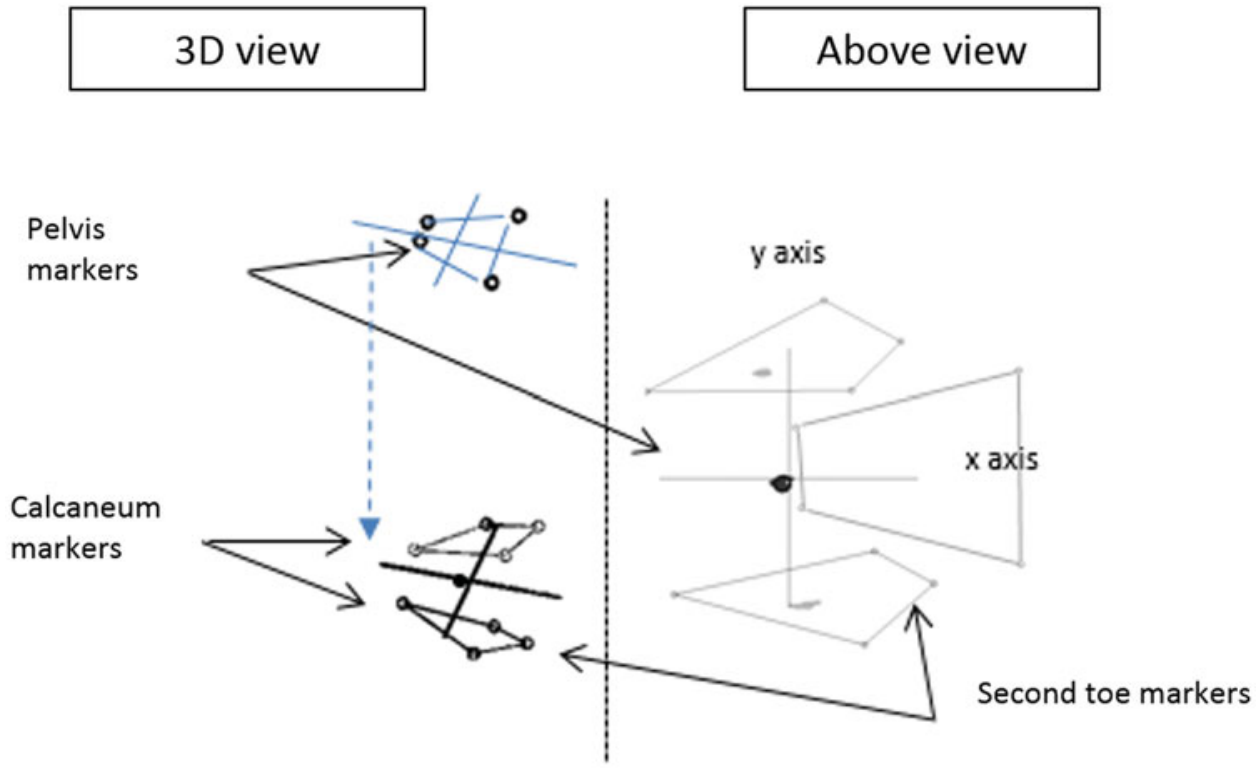

Figure 2. Anatomogravital frame used for COP position projection - the centre is the bary centre of four markers placed on the feet (the two calcaneum and the two second toe markers), the axes are obtained by the projection of the postero-anterior and mediolateral axes of the pelvis anatomical frame on the ground (level or inclined surfaces).

2. Sagittal angular position of the shank, transverse angular position and shift of the foot (as people were free to take their natural foot position).

Angular positions were computed according to [16]. Due to the lack of mobility of the ankle, for positive and negative slopes, a shift involving respectively the back foot or the forefoot was observed for some participants. To describe this adaptation, the distance between specific markers was computed along the vertical and anteroposterior directions of the global reference frame: (i) both calcaneus markers for positive slope (ii) both second toe markers for negative slope

These parameters were averaged over all the $20 \mathrm{~s}$-trials of each pair subject/foot and analysed for each individual. Mean and standard deviation were also computed over all subjects for each foot.

The load on the prosthetic limb was assessed through the normal component of the prosthetic limb ground reaction forces in the local frame attached to the contact surface (GRFy expressed as a percentage of the total weight of the subject). Prosthetic ankle, residual knee and hip internal moments were also estimated from the position of the joint centres and the ground reaction forces. In addition, the instantaneous CoP position was calculated in an anatomogravital frame defined in Figure 2 according to the study of Amabile et al. [21]. The instantaneous CoP under each foot (CoP-P for the prosthetic limb and CoP-C for the contralateral limb) was also evaluated as proposed by Winter et al. [22]. The global length of CoP trajectory was then computed as described by Prieto et al. [23]. Mediolateral and anteroposterior ranges of the CoP, CoP-P and CoP-C displacements were also assessed as suggested by Rougier et al. [24]

Mean and standard deviation were computed over all subjects for each foot.

\section{Statistics}

The differences of the parameters observed between level and the other conditions were compared using analysis of variance 
(ANOVA) with "ankle type" (UF, MPA1, MPA2, MPA3) as factors. Post hoc analyses were conducted using Tukey tests. The level of significance was set at $p<.05$.

\section{Results}

All six patients presented physiological amplitudes at the ankle/ knee/hip levels during the clinical assessment for both residual and contralateral joints. All joint and segment angular positions as well as feet positions during $20 \mathrm{~s}$-trials are shown in Appendix 1. On level ground, the relative flexion angle, between the anatomical reference position and the $20 \mathrm{~s}$-trial, of the ankles, knees, hips, pelvis and trunk, were always smaller than $2^{\circ}$ whichever the prosthetic foot used.

\section{Individual posture}

Individual joint angular positions relative to the reference during 20 s-trials on slopes are illustrated in Figure 3. On positive slope, the maximum ankle dorsiflexion obtained with MPA2 and MPA3 was $6.6^{\circ}$, whereas the dorsiflexion of UF and MPA1, were limited to a $3.9^{\circ}$. On average, a greater dorsiflexion was reached when participants wore MPA2 compared to UF ( $p$ values $=.0118$ ) and MPA1 ( $p$ values=.0146). On negative slope, the maximum ankle plantarflexion obtained with the MPA1 and MPA2 was $9.7^{\circ}$ and $8.6^{\circ}$ respectively, while using UF and MPA3, the maximum reached was $4^{\circ}$ of ankle plantarflexion. On average, the plantarflexion observed when participants used MPA2 was significantly greater than when they used their UF ( $p$ values $=.0353$ ) or MPA3 ( $p$ values $=.0193$ ) and significantly greater when using MPA1 compared to MPA3 ( $p$ values $=.0469$ ).

The angular positions of contralateral limb joints were significantly not different between the acquisitions with the different prosthetic feet (Appendix 1) regardless of the situations.

Individual prosthetic and contralateral shank flexions and feet positions are represented in Figure 4. Results showed that foot positioning varied among subjects, particularly when wearing their UF.

On positive slope, the prosthetic foot rotation was significantly greater with the UF than MPA2 ( $p$ values $=.0033$ ) and MPA3 ( $p$ values $=.0244$ ). Individual strategies of foot shift were also observed. In particular, for subject 2, a shift of the foot in both antero-posterior and vertical directions was quantified from the heel markers showing that the prosthetic foot was placed forward and the heel raised due to the inability to have the foot flat on the ground. On negative slope, the shank flexion with MPA2 was clearly greater than with MPA3 ( $p$ values=.0263). Again, some subjects adapt the position of their prosthetic foot. For example, subject 5 raised his toes with his UF as well as with MPA1 and MPA2. The same strategy could be seen for subject 4 with his UF.

\section{Normal ground reaction force, moments and centre of pressure}

\section{Load of the prosthetic limb and lower limb joint moments}

The averaged load on the prosthetic limb (Table 2) over subjects for each foot ranged between $47 \%$ and $51 \%$ of the total body weight with a standard deviation up to $6 \%$ for level ground, positive and negative slopes.

Residual knee joint moment inferior to $0.05 \mathrm{Nm} / \mathrm{kg}$ on level ground whatever the foot. On positive slope, residual knee moment increased with UF, MPA1 and MPA3 (almost 10 times for each) and remained low for MPA2 with a significant difference compared to MPA1 ( $p$ values=.0375). On negative slope, residual knee moment increased with UF and MPA3 (10 times) compared to level but remained under $0.07 \mathrm{Nm} / \mathrm{kg}$ with MPA1 and MPA2. Significant differences were obtained between moments observed with UF compared to MPA1 ( $p$ values=.0069), MPA3 compared to MPA1 ( $p$ values $=.0028$ ) as well as with UF compared to MPA2 ( $p$ values $=.0002)$ and MPA3 compared to MPA2 ( $p$ values $=.0001)$.

\section{CoP parameters}

On level ground, the CoP trajectory length was similar whatever the prosthetic foot (Appendix 1). For example, mean values were $85 \mathrm{~cm}$ (SD $12 \mathrm{~cm}$ ) and $91 \mathrm{~cm}$ (SD $14 \mathrm{~cm}$ ) with UF and MPA2 respectively. On positive slope, this parameter increased by $15 \%$ with UF, 20\% with MPA1, 3\% with MPA2 and 12\% with MPA3 compared to level ground. On negative slope, it increased by $15 \%$ with UF, $12 \%$ with MPA1, 3\% with MPA2 and 12\% with MPA3 compared to level ground.

Figure 5 shows that the AP range of CoP-C was higher than the AP range of CoP-P whatever the situations; only MPA2 resulted in small ranges (between $0.3 \mathrm{~cm}$ and $1.3 \mathrm{~cm}$ ), whereas the other feet had a modification greater than $2 \mathrm{~cm}$ ). ML range of CoP increased on slopes compared to level ground with UF, MPA1 and MPA3, whereas it remained similar with MPA2.

\section{Discussion}

The main objective of this research was to evaluate the ability of three microprocessor prosthetic ankles to adapt to the ground inclination by modifying the ankle angle in standing position without compromising stability. Body angular adaptation, lower limb joint loading and centre of pressure sway were investigated with the microprocessor prosthetic ankles (MPAs) compared to the usual ESR foot (UF) on level ground and slopes.

In standing position, it can be observed postural adaptations of non-amputee people, to keep the trunk and pelvis aligned with respect to the earth's vertical whatever the surface inclination [25]. Thus, on inclined surfaces, the ankle dorsiflexion increases in uphill condition while the ankle plantarflexion decreases in downhill condition as compared with the level condition. In the same time, knee and hip flexion angles remain lower than $2^{\circ}$ in each condition [15].

People with lower limb amputation included in this study could not adapt in the same way as non-amputee people and their adaptations changed according to the prosthetic foot. First, with the UF, ankle adaptation was limited in all static conditions, as the mobility of the ankle was only due to the carbon blade elasticity. Consequently, on positive slope, compensations were observed with both knee extension (up to $-4.8^{\circ}$ on average) and trunk flexion ( $-2.6^{\circ}$ on average). Similarly, on negative slope, the limited ankle plantarflexion adaptation of the UF was compensated by an increased knee flexion ( $9.5^{\circ}$ on average) and a pelvis retroversion (up to $5.3^{\circ}$ on average) to keep the foot flat on the floor. Second, with the MPAs, different ankle adaptations were observed. On positive slope, MPA1, which included an anterior hydraulic mechanical stop, behaved as the UF and led to similar overlying joint compensations. On the contrary, MPA2 and MPA3 permitted ankle dorsiflexion adaptation up to $6^{\circ}$ on average and demonstrated limited compensations at the overlying joints and segments. This result is consistent with the $7^{\circ}$ inclination of the slope and with the theoretical range of motion of the ankles. On negative slope, ankle plantarflexion adaptation of MPA1 (up to $9.7^{\circ}$ on average) and MPA2 (up to $8.5^{\circ}$ on average) limited knee flexion compensation to less than $2^{\circ}$ (Figure 3 ), whereas MPA3 exhibited a low ankle plantarflexion adjustment in standing position $\left(1^{\circ}\right)$. 


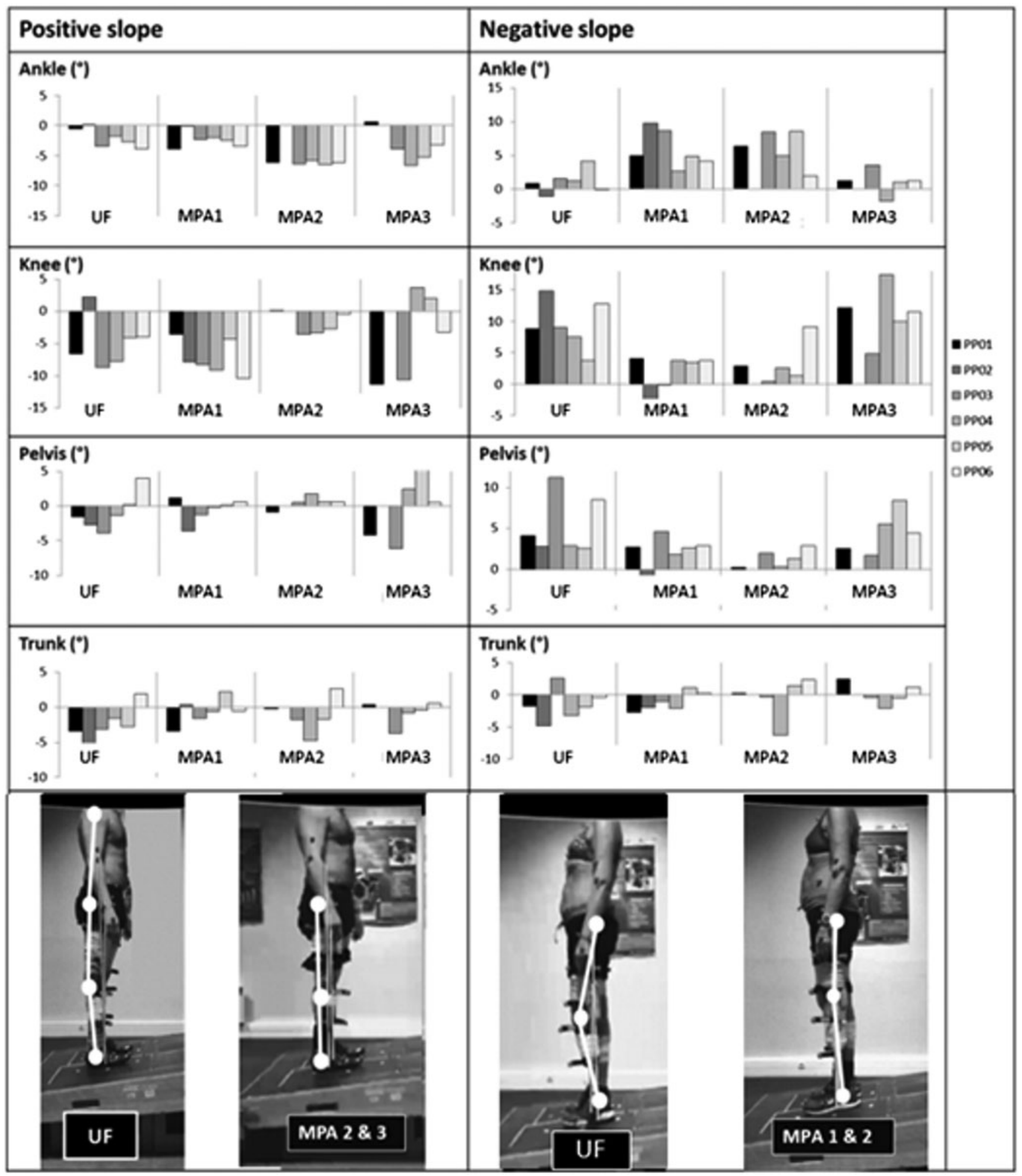

Figure 3. Sagittal angular position in degrees of the prosthetic ankle (dorsiflexion negative, plantarflexion positive), residual knee (extension negative, flexion positive) pelvis (anteversion negative, retroversion positive) and/or trunk (flexion negative, extension positive) on positive and negative slopes (in degrees) for each patient and each foot. The four photos at the bottom illustrate the angular adaptation of the lower limbs and the trunk with a MPA and the UF foot on positive slope on the left and negative slopes on the right.

In addition, as no recommendations were given for the posture taken by the subjects, several individual strategies could be quantified involving the foot position to compensate for the lack of mobility of the ankle. These strategies, only mentioned by Ernst [15], included: (i) on positive slope, either an external rotation or an anteroposterior shift of the foot to keep it flat on the ground (MPA1 and UF, Figure 4) or a raised heel resulting in a reduction of the contact surface of the prosthetic foot; (ii) on negative slope, toe rise resulting in a decrease of the contact surface (UF and MPA3, Figure 4). 


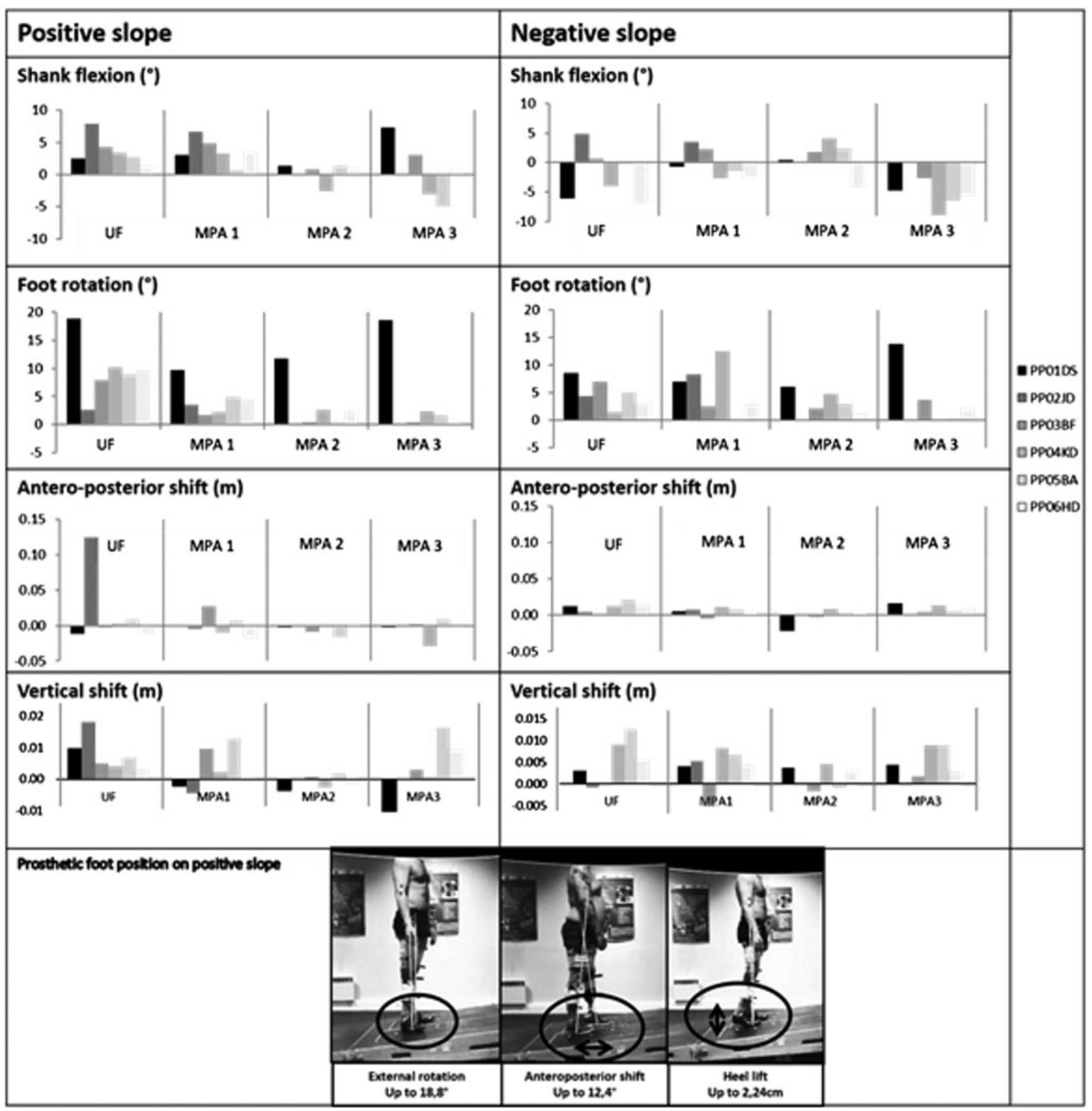

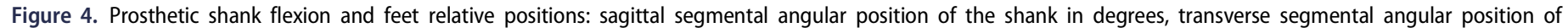

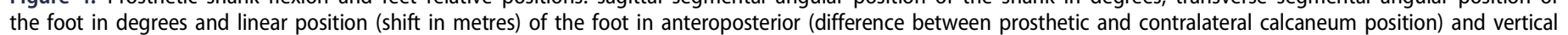

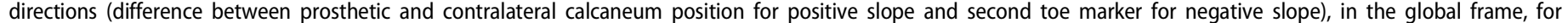
each patient and each foot. The three photographs at the bottom illustrate these UF position adaptations on positive slope.

In summary, the ankle adaptation ability directly impacted the individual angular adjustments of the overlying joints and segments in standing position on slope. The results obtained even if consistent with the theoretical capacities of the feet are interesting to assess the interaction between the foot and the person and prove the efficiency of the design in real condition.

The alignment of lower limb segments with respect to the earth's vertical can be directly related to the decrease of residual knee moments while standing on slopes [15]. In the present student, the residual knee moment was observed to be reduced in positive as well as in negative slopes when participants wore MPA2 compared to other feet (Table 2). On negative slope, low residual knee moment was also observed with MPA1. These tendencies are consistent with the findings of Ernst et al. [15]. However, the values reported in [15], averaged on four transtibial subjects were higher than in the present study. This apparent discrepancy can be related to three causes that differ in their protocol compared to the present one: (i) the acclimatization to the prosthetic foot was shorter (one week against three in the present work), (ii) no wash out period with UF was observed between foot testing, (iii) the slope was constructed with $10^{\circ}$ inclined blocks, which is less representative of an ecological condition.

Finally, CoP parameters study has been shown to be primordial to analyse static position in the literature $[7,8]$. Previous studies 


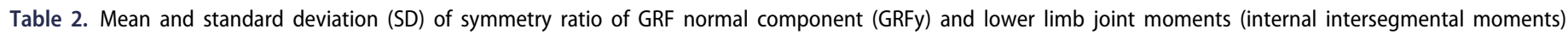

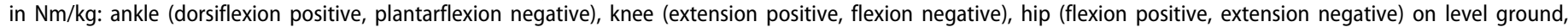
positive and negative slopes.

\begin{tabular}{|c|c|c|c|c|c|c|c|c|}
\hline \multirow[b]{2}{*}{ Foot Mean (SD) } & \multirow[b]{2}{*}{ Situation } & \multirow{2}{*}{$\begin{array}{l}\text { Prosthetic load } \\
\text { GRFy (\% of } \\
\text { total weight) }\end{array}$} & \multicolumn{3}{|c|}{ Prosthetic side } & \multicolumn{3}{|c|}{ Sound side } \\
\hline & & & $\begin{array}{c}\text { Ankle moment } \\
(\mathrm{Nm} / \mathrm{kg})\end{array}$ & $\begin{array}{l}\text { Knee moment } \\
(\mathrm{Nm} / \mathrm{kg})\end{array}$ & $\begin{array}{l}\text { Hip moment } \\
(\mathrm{Nm} / \mathrm{kg})\end{array}$ & $\begin{array}{c}\text { Ankle moment } \\
(\mathrm{Nm} / \mathrm{kg})\end{array}$ & $\begin{array}{l}\text { Knee moment } \\
(\mathrm{Nm} / \mathrm{kg})\end{array}$ & $\begin{array}{l}\text { Hip moment } \\
(\mathrm{Nm} / \mathrm{kg})\end{array}$ \\
\hline \multirow[t]{3}{*}{ UF } & Level & $50(6)$ & $-0.33(0.05)$ & $-0.02(0.09)$ & $0.21(0.11)$ & $-0.24(0.08)$ & $-0.04(0.04)$ & $0.24(0.09)$ \\
\hline & Positive slope & $47(5)$ & $-0.43(0.14)$ & $-0.18(0.09)$ & $0.16(0.08)$ & $-0.23(0.07)$ & $-0.04(0.10)$ & $0.19(0.12)$ \\
\hline & Negative slope & $49(6)$ & $-0.25(0.12)$ & $0.17(0.11)$ & $0.20(0.11)$ & $-0.28(0.06)$ & $-0.05(0.10)$ & $0.19(0.08)$ \\
\hline \multirow[t]{3}{*}{ MPA1 } & Level & $50(6)$ & $-0.25(0.07)$ & $0.02(0.06)$ & $0.21(0.10)$ & $-0.23(0.09)$ & $-0.07(0.06)$ & $0.24(0.05)$ \\
\hline & Positive slope & $50(5)$ & $-0.38(0.12)$ & $-0.20(0.09)$ & $0.19(0.09)$ & $-0.25(0.05)$ & $-0.06(0.02)$ & $0.24(0.05)$ \\
\hline & Negative slope & $50(6)$ & $-0.15(0.05)$ & $0.07(0.05)$ & $0.21(0.10)$ & $-0.25(0.11)$ & $-0.08(0.08)$ & $0.23(0.09)$ \\
\hline \multirow[t]{3}{*}{ MPA2 } & Level & $48(4)$ & $-0.25(0.07)$ & $0.05(0.04)$ & $0.19(0.08)$ & $-0.24(0.08)$ & $-0.08(0.04)$ & $0.26(0.09)$ \\
\hline & Positive slope & $51(4)$ & $-0.29(0.06)$ & $-0.02(0.03)$ & $0.19(0.10)$ & $-0.28(0.06)$ & $-0.14(0.04)$ & $0.23(0.10)$ \\
\hline & Negative slope & $49(5)$ & $-0.24(0.06)$ & $0.06(0.05)$ & $0.18(0.11)$ & $-0.22(0.07)$ & $-0.15(0.05)$ & $0.23(0.08)$ \\
\hline \multirow[t]{3}{*}{ MPA3 } & Level & $50(3)$ & $-0.29(0.08)$ & $-0.00(0.07)$ & $0.17(0.09)$ & $-0.22(0.04)$ & $-0.05(0.05)$ & $0.20(0.07)$ \\
\hline & Positive slope & $49(6)$ & $-0.44(0.13)$ & $-0.16(0.10)$ & $0.18(0.09)$ & $-0.27(0.06)$ & $-0.08(0.07)$ & $0.17(0.10)$ \\
\hline & Negative slope & $49(6)$ & $-0.16(0.09)$ & $0.20(0.06)$ & $0.17(0.13)$ & $-0.26(0.08)$ & $-0.05(0.12)$ & $0.23(0.08)$ \\
\hline
\end{tabular}

NA: non applicable.

\section{CoP ML range in mm (globally)}

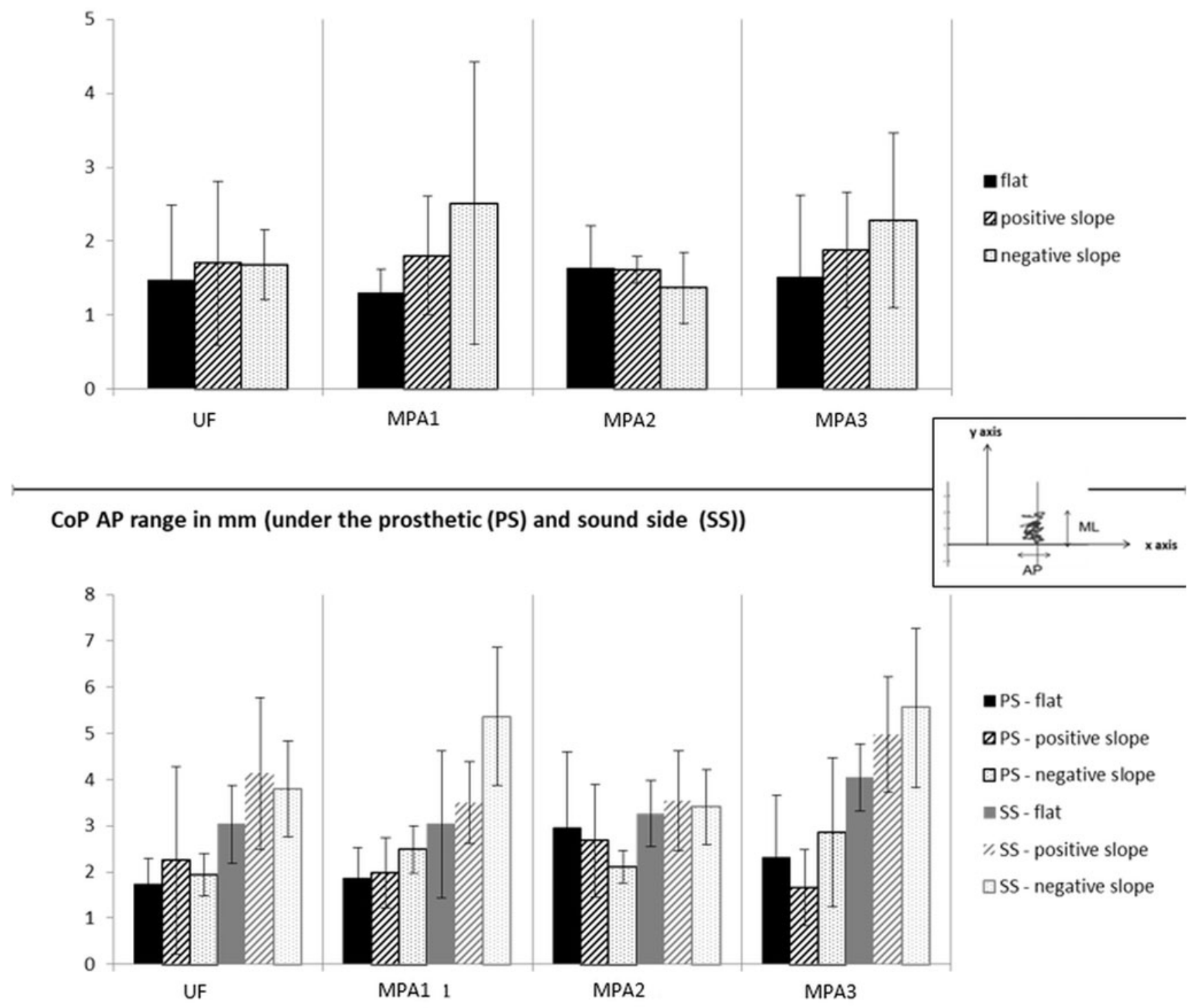

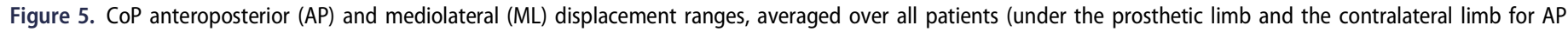
range, and under both sides for ML range), on level ground, positive and negative slopes, for each prosthetic foot. 
showed that persons with transtibial amputation managed to maintain the CoP sway in the same order of magnitude whatever the prosthetic foot on flat surface. The values of CoP trajectory length were generally lower than in the literature [26]. As shown in reviews [7,8], the differences observed could depend on the population studied and acquisition methods [7,8]. On positive slope compared to flat surface, the CoP trajectory length increased when considering participants wearing the UF and MPA1, did not show specific tendency with the MPA3 and was not affected with the MPA2.

In agreement with the literature, a much wider CoP path under the contralateral limb compared to the prosthetic limb was highlighted by CoP-C and CoP-P anteroposterior displacement ranges (Figure 5 and Appendix 1) [27]. The anteroposterior oscillations of CoP-P under the prosthetic foot has been shown to be reduced when the stiffness of the ankle increases [8,28-30]. In the literature, this was considered to result from either a small surface of contact, or a limited loading under the prosthetic side $[26,28]$. In the present study, results support a symmetrical loading (with 3\% change maximum). CoP mediolateral displacement ranges increased on slope with UF, MPA1 and MPA3, which is consistent with the use of a hip strategy to maintain postural stability as described by Mayer et al. [26]. On the contrary, with MPA2, the small CoP ML range suggested the use of physiological ankle strategy when standing on slope [26]. In summary, based on the results, participants exhibited the most symmetric balance with limited overlying compensations in standing position even on slopes when they wore MPA2 compared to other feet. This result is consistent with the large ankle mobility of this foot.

Finally, clinical functional tests revealed small differences among feet. On average (Appendix 2), only the VAS "confidence in balance" and BBS score were found higher with the MPAs than with the UF. 2MWT did not highlight any functional differences among feet but gait speed $(5.9 \mathrm{~km} / \mathrm{h})$ remained greatly above that reported in the literature $(3.1 \mathrm{~km} / \mathrm{h}$ in average on $64 \mathrm{ampu}$ tees [31]) whatever the prosthetic foot. However, some subjects in the study reported that MPA were heavy and cumbersome and felt a lack of propulsion while walking, particularly with MPA2.

\section{Limitations}

Multiple session analysis induce inherent errors due to marker replacement on computed joint flexion angles and moments [32]. A particular attention was paid to limit the impact of marker misplacement: same shoe, socket and operator; photos of the marker positions. The analysis of a self-selected standing position could hamper the interpretation of the results between the persons and with the literature but this choice was made to be as close as possible of the subject-specific physiological standing position. As most of the results are paired comparisons, these limits should not have affected the conclusions.

Parameters standard deviations were often high on slope acquisitions (Appendix 1). This may result from the variety of adaptation strategies used by the participants due to discomfort or to the lack of prosthetic ankle adaptation particularly for the UF. To overcome this limitation, an analysis of the individual behaviour of the participants was proposed in the present study, which was never reported before in previous study.

\section{Conclusion}

The analysis of standing position in standard and constraining conditions (slope) is useful to understand how people with amputation perform static balance in their daily life, especially outdoors.

According to this original study, an increased ankle mobility should permit a better posture and balance on slope. The benefits of wearing MPAs on the correct alignment of the lower limb segments and the reduction of residual knee moment were related to their design and mobility capabilities either on positive or negative slope or both. For MPA2, results also reflect the use of the prosthetic ankle in the control of CoP mobility in all situations.

Active people with transtibial amputation have naturally high requirements in terms of dynamism and propulsion. The compromise between " mobility and speed " and " comfort and balance » is essential and further gait analysis seems essential to study MPAs relevance.

\section{Acknowledgements}

The authors would like to thank Didier Azoulay and Geneviève Leroy from CERAH.

\section{Disclosure statement}

The authors declare that there is no conflict of interest. All authors contributed equally in the preparation of this manuscript.

\section{ORCID}

H. Pillet (iD http://orcid.org/0000-0002-0263-5910

\section{References}

[1] Gailey R, Allen K, Castles J, et al. Review of secondary physical conditions associated with lower-limb amputation and long-term prosthesis use. JRRD. 2008;45(1):15-29.,

[2] Schmalz T, Altenburg B, Ernst M, et al. O 010-Ramp walking with abruptly changing inclines: motion pattern of $\Pi$ amputees fitted with a microprocessor-controlled and a conventional prosthetic foot. Gait Posture. 2018;65:19.

[3] Fradet L, Alimusaj M, Braatz F, et al. Biomechanical analysis of ramp ambulation of transtibial amputees with an adaptive ankle foot system. Gait Posture. 2010;32(2):191-198.

[4] Struchkov V, Buckley JG. Biomechanics of ramp descent in unilateral trans-tibial amputees: comparison of a microprocessor controlled foot with conventional ankle-foot mechanisms. Clin. Biomech. 2016;32:164-170.

[5] Delussu AS, Brunelli S, Paradisi F, et al. Assessment of the effects of carbon fiber and bionic foot during overground and treadmill walking in transtibial amputees. Gait Posture. 2013;38(4):876-882.,

[6] Horak FB, Nashner LM, Diener HC. Postural strategies associated with somatosensory and vestibular loss. Brain Res. 1990;82(1):167-177.

[7] Ku PX, Abu Osman NA, Wan Abas WAB. Balance control in lower extremity amputees during quiet standing: a systematic review. Gait Posture. 2014;39(2):672-682.

[8] Seth M, Lamberg E. Standing balance in people with transtibial amputation due to vascular causes : a literature review. Prosthet Orthot Int. 2017;41(4):345-355.

[9] Winter DA. Human blance and posture control during standing and walking. Gait Posture. 1995;3(4):193-214.

[10] Norvell DC, Czerniecki JM, Reiber GE, et al. The prevalence of knee pain and symptomatic knee osteoarthritis among 
veteran traumatic amputees and nonamputees. Arch Phys Med Rehabil. 2005;86(3):487-493.,

[11] Struyf PA, van Heugten CM, Hitters MW, et al. The prevalence of osteoarthritis of the intact hip and knee among traumatic leg amputees. Arch Phys Med Rehabil. 2009; 90(3):440-446.

[12] Morgenroth DC, Segal AD, Zelik KE, et al. The effect of prosthetic foot push-off on mechanical loading associated with knee osteoarthritis in lower extremity amputees. Gait Posture. 2011;34(4):502-507.,

[13] Geurts ACH, Mulder TW. Reorganisation of postural control following lower limb amputation: theoretical considerations and implications for rehabilitation. Physiother Theory Pract. 1992;8(3):145-157.

[14] Pitta F, Troosters T, Spruit MA, et al. Characteristics of physical activities in daily life in chronic obstructive pulmonary disease. Am J Respir Crit Care Med. 2005;171(9):972-977.

[15] Ernst M, Altenburg B, Bellmann M, et al. Standing on slopes - How current microprocessor-controlled prosthetic feet support transtibial and transfemoral amputees in an everyday task. J Neuroeng Rehab. 2017;14(1):1-16.

[16] Pillet $H$, Drevelle $X$, Bonnet $X$, et al. APSIC: Training and fitting amputees during situations of daily living. Irbm. 2014; 35(2):60-65.

[17] Bell AL, Pedersen DR, Brand RA. A comparison of the accuracy of several hip center location prediction methods. J Biomech. 1990;23(6):617-621.

[18] Miller WC, Speechley M, Deathe AB. Balance confidence among people with lower limb amputation. Phys Ther. 2002;82(9):856-865.

[19] Berg K, Wood-Dauphinee S, Williams Jl, et al. Measuring balance in the elderly: preliminary development of an instrument. Physiother Canada. 1989;41(6):304-311.

[20] Reid L, Thomson P, Besemann M, et al. Going places: does the two-minute walk test predict the six-minute walk test in lower extremity amputees? J Rehabil Med. 2015;47(3): 256-261.

[21] Amabile $C$, Pillet $H$, Lafage $V$, et al. A new quasi-invariant parameter characterizing the postural alignment of young asymptomatic adults. Eur Spine J. 2016;25(11):3666-3674.
[22] Winter DA, Prince F, Patla A. Validity of the inverted pendulum model of balance in quiet standing. Gait Posture. 1997;2(5):153-154.

[23] Prieto TE, Lovett EG, Myklebust BM, et al. Measures of postural steadiness: differences between healthy young and elderly adults. IEEE Trans Biomed Eng. 1996;43(9):956-966.

[24] Rougier P, Belaid D, Cantalloube S, et al. Quiet postural control of patients with total hip arthroplasty following joint arthritis. Motor Control. 2008;12(2):136-150.

[25] Leroux A, Fung J, Barbeau H. Postural adaptation to walking on inclined surfaces: II. Strategies following spinal cord injury. Clin. Neurophysiol. 2006;117(6):1273-1282.

[26] Mayer Á, Tihanyi J, Bretz K, et al. Adaptation to altered balance conditions in unilateral amputees due to atherosclerosis: a randomized controlled study. BMC Musculoskelet. Disord. 2011;12(1):118.

[27] Hlavackova P, Franco C, Diot B, et al. Contribution of each leg to the control of unperturbed bipedal stance in lower limb amputees: new insights using entropy. PLoS One. 2011;6(5):e19661-7.

[28] Vrieling $\mathrm{AH}$, van Keeken $\mathrm{HG}$, Schoppen $\mathrm{T}$, et al. Balance control on a moving platform in unilateral lower limb amputees. Gait Posture. 2008;28(2):222-228.

[29] Arifin N, Abu Osman NA, Ali S, et al. Postural stability characteristics of transtibial amputees wearing different prosthetic foot types when standing on various support surfaces. Sci World J. 2014;2014:1.

[30] Nederhand MJ, Van Asseldonk EHF, Van der Kooij H, et al. Dynamic Balance Control (DBC) in lower leg amputee subjects; contribution of the regulatory activity of the prosthesis side. Clin Biomech. 2012;27(1):40-45.

[31] Gremeaux V, Damak S, Troisgros O, et al. Selecting a test for the clinical assessment of balance and walking capacity at the definitive fitting state after unilateral amputation: a comparative study. Prosthet Orthot Int. 2012;36(4): 415-422.

[32] Della Croce U, Leardini A, Chiari L, et al. Human movement analysis using stereophotogrammetry Part 4: assessment of anatomical landmark misplacement and its effects on joint kinematics. Gait Posture. 2005;21(2): 226-237. 
Appendix 1. Mean values and standard deviation of computed parameters over all subjects for the four prosthetic feet in all situations

\begin{tabular}{|c|c|c|c|c|c|c|c|c|c|c|c|c|c|c|}
\hline \multirow{2}{*}{$\begin{array}{l}\text { Situations } \\
\text { Prosthetic foot } \\
\end{array}$} & & & \multicolumn{4}{|c|}{ Level } & \multicolumn{4}{|c|}{ Positive slope } & \multicolumn{4}{|c|}{ Negative slope } \\
\hline & & & UF & MPA 1 & MPA 2 & MPA 3 & UF & MPA 1 & MPA 2 & MPA 3 & UF & MPA 1 & MPA 2 & MPA 3 \\
\hline \multicolumn{15}{|c|}{ Position of the subject } \\
\hline \multirow[t]{12}{*}{ Sagittal plane $\left({ }^{\circ}\right)$} & Ankle & ss & $-0.39(0.5)$ & $-0.8(1.5)$ & $-0.4(1.3)$ & $-0.31(1.5)$ & $-9.14(1.8)$ & $-8.6(2.0)$ & $-7(4.4)$ & $-9.98(4.2)$ & $7.07(2.7)$ & $7.45(1.4)$ & $6.9(1.8)$ & $6.9(2.3)$ \\
\hline & & PS & $-0.33(0.8)$ & $-0.6(0.9)$ & $-0.2(0.9)$ & $-0.37(1.4)$ & $-2.03(1.6)$ & $-2.36(1.3)$ & $-6.2(0.2)$ & $-3.7(2.7)$ & $1.12(1.8)$ & $5.8(2.8)$ & $6.1(2.7)$ & $1.08(1.9)$ \\
\hline & Knee & ss & $1.61(1.7)$ & $0.1(2.5)$ & $0.6(1.5)$ & $0.48(1.4)$ & $2.79(4.7)$ & $1.8(2.7)$ & $-0.4(3.1)$ & $-0.14(5.7)$ & $2.71(5.0)$ & $-1.2(5.4)$ & $-3.9(2.6)$ & $-0.45(6.8)$ \\
\hline & & PS & $0.47(0.9)$ & $0.7(1.2)$ & $1.2(2.7)$ & $1.19(1.2)$ & $-4.81(3.9)$ & $-7.2(2.7)$ & $-2(1.7)$ & $-3.88(7.0)$ & $9.46(3.9)$ & $1.7(3.5)$ & $2.7(4.0)$ & $11.19(4.5)$ \\
\hline & Hip & ss & $0.5(2.0)$ & $1.7(0.6)$ & $1.4(1.5)$ & $2(5.1)$ & $-1.2(5.6)$ & $1.1(1.9)$ & $3.4(5.0)$ & $4(3.0)$ & $1.6(2.2)$ & $0.3(5.1)$ & $4.3(2.8)$ & $5.4(4.2)$ \\
\hline & & PS & $1.4(0.7)$ & $1(1.6)$ & $1.3(1.4)$ & $1.7(4.3)$ & $1.2(6.8)$ & $3.5(3.6)$ & $1.8(2.0)$ & $3.3(3.1)$ & $0.6(3.5)$ & $-0.2(3.5)$ & $-0.9(1.0)$ & $-0.8(3.5)$ \\
\hline & Pelvis & & $1.2(1.3)$ & $1(1.2)$ & $1.58(1.3)$ & $1.73(3.1)$ & $-0.91(2.7)$ & $-0.5(1.7)$ & $0.8(0.6)$ & $-0.26(5)$ & $5.32(3.7)$ & $2.3(1.8)$ & $1.3(1.1)$ & $4.51(2.7)$ \\
\hline & Trunk & & $-1.23(1.6)$ & $-0.1(2.0)$ & $-0.2(3.3)$ & $0.01(1.3)$ & $-2.55(2.7)$ & $-0.6(1.9)$ & $-1(2.8)$ & $-0.83(1.7)$ & $-1.6(2.5)$ & $-1.1(1.5)$ & $-0.5(3.4)$ & $0.1(1.8)$ \\
\hline & Shank & sS & $-0.38(0.5)$ & $-0.1(1.9)$ & $0(1.2)$ & $-0.3(1.4)$ & $-2.15(1.6)$ & $-2.2(1.7)$ & $-0.3(2.3)$ & $-3.11(4.1)$ & $2.3(5.8)$ & $0.9(1.2)$ & $0.1(2.2)$ & $-0.2(2.7)$ \\
\hline & & PS & $-0.15(0.8)$ & $-0.33(1.2)$ & $-0.4(1.0)$ & $-0.88(2.4)$ & $3.7(2.3)$ & $3.7(2.0)$ & $0.4(1.7)$ & $0.62(4.9)$ & $-2.0(4.5)$ & $-0.3(2.6)$ & $0.8(3.2)$ & $-5.7(2.3)$ \\
\hline & Antero & erior shift $(\mathrm{cm})$ & & & & & $1.18(5.3)$ & $0.00(1.6)$ & $-0.05(0.8)$ & $0.05(1.4)$ & & & & \\
\hline & Vertica & $\mathrm{ft}(\mathrm{cm})$ & & & & & $0.8(0.5)$ & $0.3(0.7)$ & $-0.1(0.2)$ & $0.4(1.0)$ & $0.5(0.5)$ & $0.4(0.5)$ & $-0.2(0.3)$ & $0.5(0.3)$ \\
\hline \multirow[t]{2}{*}{ Horizontal plane $\left({ }^{\circ}\right)$} & Foot & ss & $7.83(12.6)$ & $0.9(10.5)$ & $3.2(11.4)$ & $5.09(10.3)$ & $7.21(13.0)$ & $0.3(11.2)$ & $0.6(11.4)$ & $6.21(13.0)$ & $6.1(9.7)$ & $2.3(8.5)$ & $3.5(6.9)$ & $3.6(9.5)$ \\
\hline & & PS & $6.2(5.2)$ & $3.3(4.0)$ & $7.1(3.3)$ & $6.57(3.9)$ & $9.71(5.2)$ & $4.4(2.9)$ & $3.4(4.8)$ & $4.78(7.7)$ & $4.9(2.6)$ & $5.6(4.5)$ & $3.4(2.0)$ & $3.9(5.7)$ \\
\hline \multicolumn{15}{|c|}{ Variations of standing stability $=$ COP parameters } \\
\hline Cop trajectory $(\mathrm{cm})$ & & Global & $85(12)$ & $89(20)$ & $91(13)$ & $83(11)$ & $98(23)$ & $107(30)$ & $94(5)$ & $93(10)$ & $98(24)$ & $100(20)$ & $94(5)$ & $93(12)$ \\
\hline \multirow[t]{2}{*}{ AP range $(\mathrm{cm})$} & & SS & $3.03(0.84)$ & $3.03(1.59)$ & $3.26(0.72)$ & $4.04(0.72)$ & $4.13(1.64)$ & $3.5(0.88)$ & $3.54(1.07)$ & $4.97(1.25)$ & $3.8(1.04)$ & $5.36(1.49)$ & $3.41(0.81)$ & $5.56(1.72)$ \\
\hline & & ps & $1.73(0.56)$ & $1.87(0.65)$ & $2.96(1.63)$ & $2.31(1.36)$ & $2.25(2.03)$ & $1.98(0.76)$ & $2.68(1.22)$ & $1.66(0.82)$ & $1.94(0.46)$ & $2.49(0.51)$ & $2.11(0.35)$ & $2.86(1.62)$ \\
\hline ML range $(\mathrm{cm})$ & & Global & $1.47(1.01)$ & $1.3(0.32)$ & $1.63(0.57)$ & $1.51(1.11)$ & $1.7(1.11)$ & $1.8(0.80)$ & $1.61(0.18)$ & $1.88(0.78)$ & $1.68(0.48)$ & $2.51(1.91)$ & $1.37(0.48)$ & $2.27(1.18)$ \\
\hline
\end{tabular}

AP: anteroposterior direction; CoP: center of pressure; ML: mediolateral direction; MPA: microprocessor prosthetic ankle; PS: prosthetic side; SS: sound side; UF: usual foot.

Appendix 2. Functional results for each subject (PP01 to PP06) and for each foot and on average for each foot

\begin{tabular}{|c|c|c|c|c|c|c|}
\hline Foot & & $\begin{array}{c}\text { EVA } \\
\text { confidence } \\
\text { in balance } \\
(/ 10)\end{array}$ & BBS total $(/ 56)$ & $2 \mathrm{MWT}(\mathrm{m})$ & $\begin{array}{c}\text { Gait speed } \\
\text { on } 2 \text { minutes } \\
\text { (calculated } \\
\text { with the } \\
2 \mathrm{MWT} \text {, in } \\
\mathrm{km} / \mathrm{h} \text { ) } \\
\end{array}$ & $A B C(/ 45)$ \\
\hline \multirow[t]{2}{*}{ ESR } & Mean & 6,9 & 53 & 197 & 5,91 & 38 \\
\hline & Sd & 1,1 & 2 & 35 & 1,05 & 8 \\
\hline PP01 & & 5 & 54 & 156 & 4,68 & 24 \\
\hline PPO2 & & 7 & 50 & 158 & 4,74 & 35 \\
\hline PP03 & & 6,5 & 53 & 184 & 5,52 & 35 \\
\hline PPO4 & & 7 & 56 & 230 & 6,9 & 42 \\
\hline PP05 & & 8 & 54 & 231 & 6,93 & 45 \\
\hline PP06 & & 8 & 53 & 220 & 6,6 & 45 \\
\hline \multirow[t]{2}{*}{ NGF1 } & Mean & 7,2 & 55 & 209 & 6,27 & 37 \\
\hline & Sd & 1,8 & 2 & 27 & 0,8 & 7 \\
\hline PP01 & & 6,5 & $\mathrm{NC}$ & $\mathrm{NC}$ & NC & NC \\
\hline $\mathrm{PPO2}$ & & 8 & 55 & 184 & 5,52 & 40 \\
\hline $\mathrm{PP} 03$ & & 9 & 51 & 177 & 5,31 & 37 \\
\hline PP04 & & 8 & 56 & 237 & 7,11 & 42 \\
\hline PP05 & & 4 & 56 & 227 & 6,81 & 25 \\
\hline PP06 & & 7,5 & 56 & 219 & 6,57 & 40 \\
\hline \multirow[t]{2}{*}{ NGF2 } & Mean & 8,1 & 54 & 204 & 6,12 & 39 \\
\hline & $S d$ & 0,9 & 2 & 32 & 0,95 & 8 \\
\hline PP01 & & 7,5 & 52 & 171 & 5,13 & 38 \\
\hline PP03 & & 9 & 53 & 171 & 5,13 & 26 \\
\hline PP04 & & 9 & 56 & 239 & 7,17 & 43 \\
\hline PP05 & & 8 & 56 & 224 & 6,72 & 45 \\
\hline PP06 & & 7 & 54 & 217 & 6,51 & 45 \\
\hline \multirow[t]{2}{*}{ NGF3 } & Mean & 7,9 & 54 & 209 & 6,27 & 38 \\
\hline & $\mathrm{Sd}$ & 1,3 & 1 & 27 & 0,8 & 7 \\
\hline PP01 & & 7 & 55 & 171 & 5,13 & 30 \\
\hline PP03 & & 7 & 52 & 192 & 5,76 & 31 \\
\hline PP04 & & 7 & 55 & 230 & 6,9 & 41 \\
\hline PP05 & & 10 & 54 & 234 & 7,02 & 45 \\
\hline PP06 & & 8,5 & 53 & 219 & 6,57 & 42 \\
\hline
\end{tabular}

ABC: Activity-specific Balance Confidence; BBS: Berg Balance Scale; MPA: microprocessor prosthetic ankle; 2MWT: two minutes walking test; SD: standard deviation; UF: usual foot. 